\title{
Dichotomies in the Fluvial and Alluvial Fan Deposits of Aeolis Dorsa, Mars: Implications for Weathered Sediment and Paleoclimate
}

\section{Supplemental File}

This supplemental file contains the local area maps and topographic profiles used to derive stratigraphic columns. Each map and topographic profile includes a full description of the mapped units and the reasoning to infer stratigraphic relationships. This information is summarized in the manuscript in Table 2 and Figure 10.

\section{Methods for mapping and stratigraphy}

Mapped units of the four local areas were distinguished by differences in landform morphology, surface texture, and surface albedo. Units were then described and interpreted to yield the formative processes and conditions of each local area.

Stratigraphic columns from local areas were correlated by similar geomorphology (e.g., thin features are correlated) or sedimentary units (e.g., meander fluvial deposits are correlated). Correlated stratigraphic columns are used to interpret any spatial heterogeneity and change of sedimentary environments in the Aeolis Dorsa region.

Without observations in cross-section, thicknesses of fluvial units must be inferred. We estimate thicknesses of fluvial units from width-to-thickness (W/T) ratios of deposits on Earth (Gibling, 2006). Although a similar W/T ratio has not been demonstrated on Mars, we use this terrestrial value as a reasonable means of separating fluvial deposits from substrate material. Where feature relief is greater than the inferred thickness, we assume the lower portion of the feature to be MFF, suggesting that it was the substrate of fluvial activity. There are several caveats regarding the use of a W/T ratio to estimate thickness. First, W/T ratios were derived from data with large ranges (Gibling, 2006), which contribute uncertainty to estimates of thickness. Second, the ratio applies to unconfined channels, which may not be the case for some of the Aeolis Dorsa deposits (Cardenas and Mohrig, 2015). Third, the ratio applies to single-story channel deposits and would not be accurate for estimating the thicknesses of multi-story deposits (Gibling, 2006).

\section{Mapping of Area 35}

Area 35 is adjacent to the eastern margin of Zephyria Planum, which appears in the northeast corner of the Area 35 map (Figure SI-1). Type 2 flat features, interpreted as channel fill, form a network orthogonal to the margin of Zephyria Planum. We interpret these features to be fluvial channel fills based on their nondescript upper surfaces, which are similar to terrestrial channel fill deposits (Figure 4). This network of fluvial channel fills connects to wide Type 1 flat features in central and eastern portions of Area 35. The topography of Type 1 flat feature includes meter-scale ridges and swales (Figure SI-2B), similar to the eroded forms of terrestrial meander deposits. Thin features have alternating sections of sharp-crests and flat upper surfaces, which are interpreted here as partially eroded channel fills (Figure SI-2B) based on their similarity to terrestrial channel fills. A mounds unit (Figure 11E) with a bumpy surface texture appears next to the fluvial deposits. The morphology of the mounds unit is unlike the linear and sinuous 
morphologies of fluvial deposits and yardangs, and suggests some other mode of widespread deposition (e.g., airfall).

Fans features appear in the northwest and southeast portions of the area (dark pink) and near the mounds unit. Fan ridges radiate from fan apices and have flat upper surfaces, which are consistent with channelized fluvial deposits (Table 1). Twin-parallel ridges are also present and are consistent with debris-flow levees (Table 1; Figure SI-2C). Each fan is connected to a network of ridges (light pink) with structureless and flat upper surfaces (similar to Type 2 features). We interpret these as paired tributary networks and distributary fans of alluvial fan systems.

Yardangs appear throughout Area 35 and represent the deposition of MFF. The northeast-southwest orientations of these yardangs suggest aeolian abrasion by a northeast-southwest paleo-wind in this area.

\section{Stratigraphy of Area 35}

From our mapping of Area 35 (Figure SI-1), we identified 6 separate units, which we examine in order to derive the stratigraphic column (Figure 10). The drainage network unit in profile A-A' (Figure SI-3) and the network of fluvial channel fills form near the topographic high of Zephyria Planum and dip away (southwestward) from the planum scarp. We postulate that Zephyria Planum once extended further towards the southwest and was in contact with a network of fluvial channels. Zephyria Planum has since experienced cliff-retreat towards the northeast, perhaps in response to the hydrologic activity that formed the networks, during which this network became inverted. If this postulate is accurate, it suggests that Zephyria Planum is the oldest unit in Area 35 because it was in place prior to hydrologic activity. Therefore, we place the Zephyria Planum unit at the bottom of the stratigraphic column (Figure 10).

Flat features are older fluvial deposits in Area 35 as indicated by superposition beneath thin fluvial channel fills (Figure SI-3). The widths of meander deposits and channel fills are up to $1 \mathrm{~km}$. This width suggests a proportionate thickness, based on our posited W/T ratio, of $\sim 33$ meters. However, the average relief of these fluvial deposits is on the order of 100 meters, suggesting that the bottom 67 meters is MFF. Because this unit shows meander deposits on its upper surface, cross-stratification symbols appear in the column to indicate lateral accretion sets (Figure 10).

Superjacent to the flat feature unit, thin fluvial channel fills form with average widths of $\sim 60$ meters, suggesting a proportionate deposit thickness of 2 meters. These thin channel fills have reliefs of $\sim 25$ meters, suggesting that the bottom 23 meters of material is MFF (Figure SI-3). Thin channel fills set within a superposing layer of MFF are consistent with thin feature flow paths, which cut across meander deposits and suggest that the underlying topography had minimal influence on the formation of later channel fills (Burr et al., 2009).

The mounds unit appears next to and is cut by the alluvial fans unit (Figure SI$2 \mathrm{C}$ ), indicating that the mounds are older than the fans. The topographic profile C-C' was drawn over a mound and plotted on the profile A-A' for comparison (Figure SI-3). Profile C-C' shows the mounds unit has at least 50 meters of relief. We place a broken contact between the mounds unit and the unit of thin channel fills because no indication of relative age was observed in Area 35 (Figure 10). 
Alluvial fans have thicknesses of at least 50 meters, as shown in topographic profiles A-A' and B-B' (Figure SI-3). An erosional unconformity is suggested by the cross-cutting relationship between the mounds and fans. Based on these relationships, we infer that mound material composes some of the fan sediment and represent mound material as brown clasts in the stratigraphic column (Figure 10).

Yardangs are stacked on top of alluvial fans and also appear between inverted fluvial deposits (Figure SI-3A). These relationships indicate that yardangs have the youngest relative age and formed after the topographic inversion of fluvial deposits. Yardangs have an average thickness of $\sim 25$ meters. We add arrows to the stratigraphic column for Area 35 to indicate the direction (NE-SW) of the paleo-wind that abraded the yardangs (Figure 10).

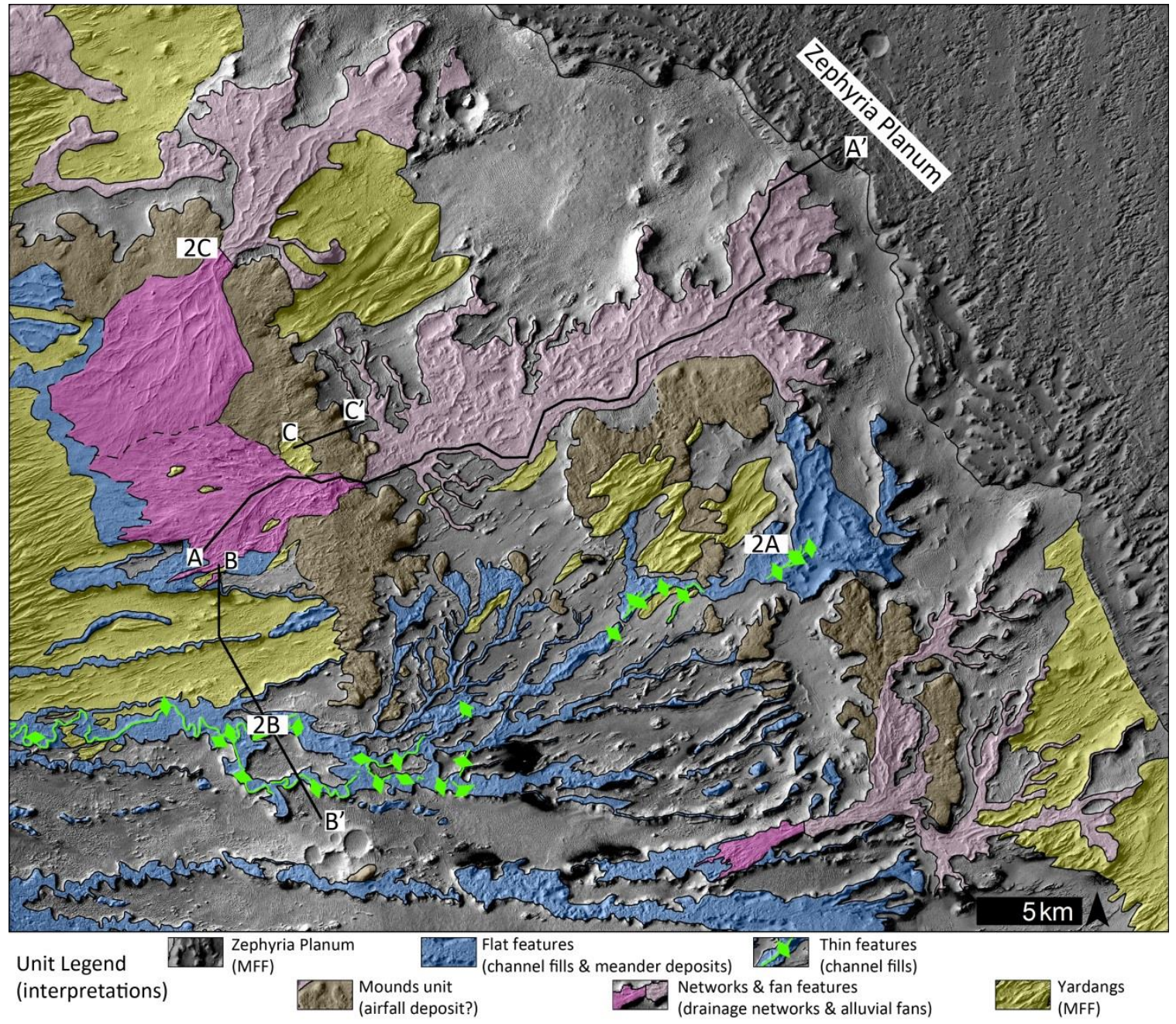

Figure SI-1. Area 35 mapped with 6 units, as they appear in the CTX mosaic. Green lines with diamonds delineate channel fills (i.e., thin features). The drainage network unit (light pink) and alluvial fan unit (dark pink) are interpreted to form fan systems, with respectively tributary and distributary components. Numbered locations correspond to Supplemental Figure locations. Letters correspond to the ends of topographic profiles (Figure SI-3) derived from CTX stereo DTMs. 

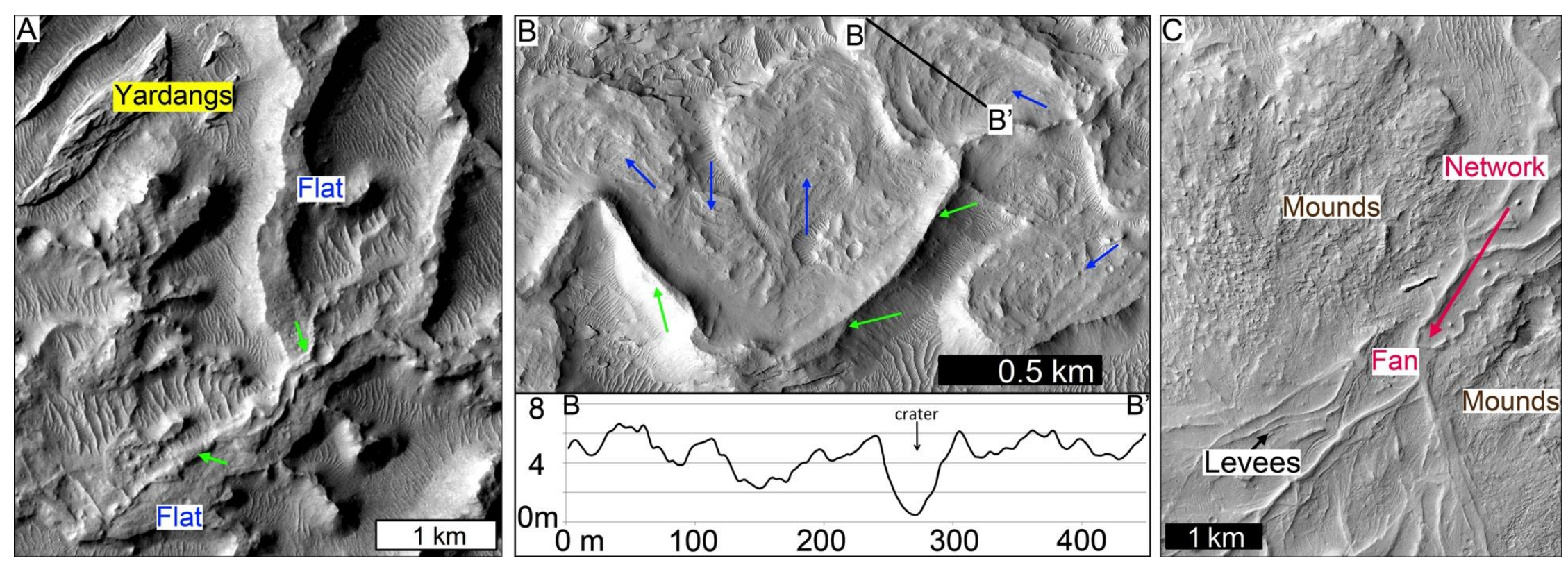

Figure SI-2. (A) Networked Type 2 flat features have textureless upper surfaces consistent with the morphology of fluvial channel fills. A thin fluvial channel fill (green arrows) is stacked on top of the flat feature suggesting reoccupation of the same paleovalley. (B) Portion of HiRISE image (PSP_009623_1755) and corresponding DTM profile B-B' show the topography of a Type 1 flat feature with meter-scale ridges and swales (blue arrows) interpreted to be meander deposits (Table 1). A thin fluvial channel fill (green arrows) is superposed on the meander deposits. (C) A portion of HiRISE image (ESP_035468_1755) shows the rough surface of the mounds unit, which is adjacent to and cut by ridges of the alluvial fan unit (pink arrow). Here and farther downslope, this fan shows parallel ridges, which are similar to the morphology of debris-flow levees. 


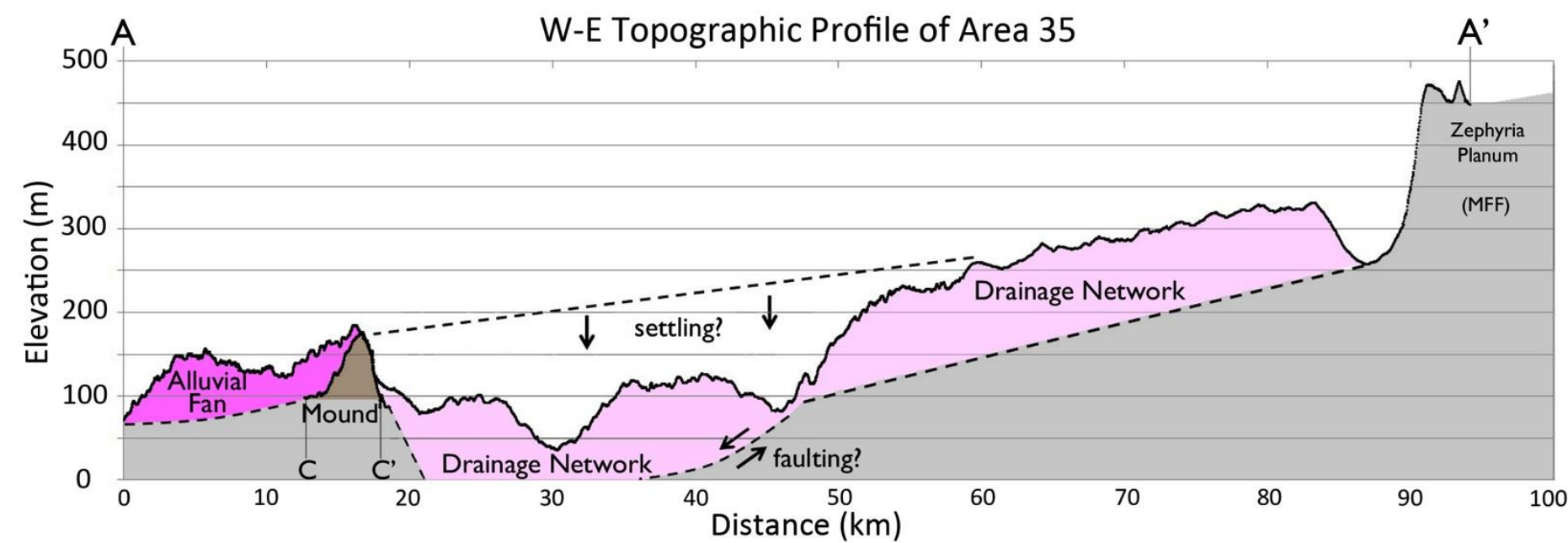

B

N-S Topographic Profile of Area 35

B'

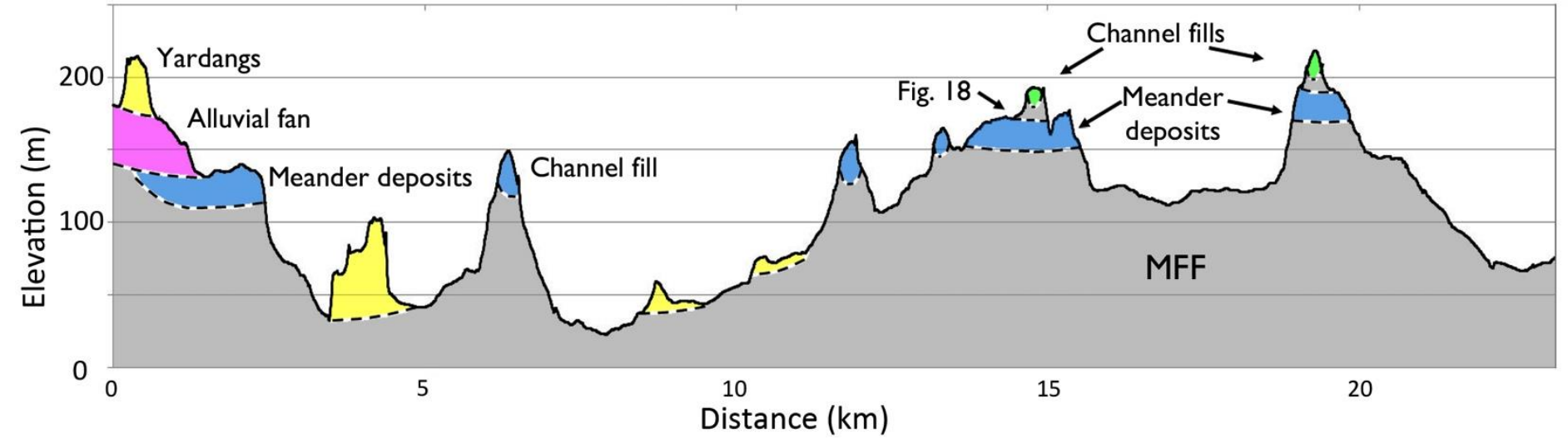

Figure SI-3. Profile A-A' shows the relationships among Zephyria Planum, alluvial fan, and drainage network units. Hypotheses for the undulations along profile A-A' include settling or faulting (Lefort et al., 2012). Profile B-B' shows the topography over fluvial, alluvial, yardang units, and the underlying MFF. Profile $\mathrm{C}-\mathrm{C}^{\prime}$ is shown on the diagram for profile A-A' in order to compare the mound and the adjacent alluvial fan. 


\section{Mapping of Area 40}

Area 40 is situated in a relative flat region (Figure 9) and closer to the current location of the global dichotomy boundary than Area 35. Within this area, we distinguish two units of flat features, i.e., unit I and unit II, shaded purple and blue, respectively, on our mapping. In the eastern portion of Area 40, unit I forms well-connected, sub-parallel networks of Type 2 flat features interpreted as networks of fluvial channel fill based on their flat-topped textureless morphology (Table 1). We suggest these networks connect in the subsurface with wide Type 1 flat features in the northwestern portions of Area 40 (i.e., they are partially covered by the mounds unit, Figure SI-4). The Type 1 flat features of unit I have meter-scale ridges and swales (profile B-B'), consistent with the topography of eroded meander deposits. Meander deposits in Area 40 indicate regular supplies of water and sediment during formation, and stable floodplains to maintain meander dynamics.

Unit II has dendritic-like networks of Type 2 flat features (i.e., channel fills) in the southern portion of Area 40. The morphologies (e.g., junction angles) of these networks are similar to the morphologies of networks in Area 35. Networks of unit II also connect to Type 1 flat features in the northwest portion of Area 40. These Type 1 features have been interpreted as meandering fluvial deposits. Thus, Area 40 has two units of flat features (unit I and unit II); each with networks of fluvial channel fills connects to fluvial meander deposits. Units I and II are distinguishable by their different junction angles. Unit I forms a sub-parallel network of channel fills, whereas unit II forms a dendritic network of channel fills (Figure SI-4).

Thin features appear on top of meander deposits in the northwestern portion of Area 40. As in Area 35, we interpret these features as fluvial channel fills superposed on the fluvial meander deposits (Figure SI-5C).

A mounds unit obscures features across the middle of Area 40 (Figure SI-4). The mounds unit has many sinuous troughs, some of which connect to lobes. The widths of these lobes increase away from the termini of troughs suggesting lateral expansion during deposition. We interpret these troughs and lobes as alluvial channels and debris flow lobes, respectively. The formation of these deposits requires infrequent hydrologic activity, transport of mud, and loss of channel confinement.

\section{Stratigraphy of Area 40}

Mapping of Area 40 identified 5 units, which we examine in conjunction with a topographic profile to derive the stratigraphic column (Figure 10). Flat features unit I includes channel fills with an average width of $~ 300$ meters, which suggests channel fills are $~ 10$ meters thick. Meandering fluvial deposits of unit I appear in the northwestern portions of Area 40. The lower contact of meandering fluvial deposits is not apparent, but thicknesses are suggested to be greater than 10 meters based on widths of more than 1 kilometer. Meander deposits of unit II have widths up to 1.5 kilometers, suggesting thicknesses of $\sim 50$ meters. Two large reaches of unit II separate and reconnect in the northwestern corner of Area 40, suggesting that unit II cuts through unit I. Therefore, we place a 50-meter-thick unit II above unit I in the column for Area 40 (Figure 10).

The topographic profile A-A' is drawn over several units in Area 40 and shows that the relief of thin fluvial channel fills is $\sim 10$ meters. The average width of thin fluvial channel fills is $\sim 50$ meters, suggesting that the deposit is $\sim 2$ meters thick. Therefore, we 
place a 2-meter-thick fluvial channel fill unit and 8-meter-thick unit of MFF above flat features unit II in the stratigraphic column.

Mapping of Area 40 suggests the mounds unit covers the fluvial units. Profile AA' shows that the relief of the mounds unit is $\sim 150$ meters (Figure SI-6), but this relief varies across the area. We place a 150-meter-thick mounds unit in the stratigraphic column (Figure 10), but add a jagged lower contact to indicate an uncertain thickness.

Troughs and lobes are evidence of erosion and alluvial sedimentation, largely occurring within the mounds unit (Figure SI-5D). The topographic profile A-A' shows the debris flow lobe to be $\sim 15$ meters thick. Trough erosion suggests an erosional unconformity between the debris flow lobes and the mounds unit. We place 15-meterthick alluvial unit, composed of mounds material (i.e., brown clasts) in the stratigraphy for Area 40 (Figure 10).

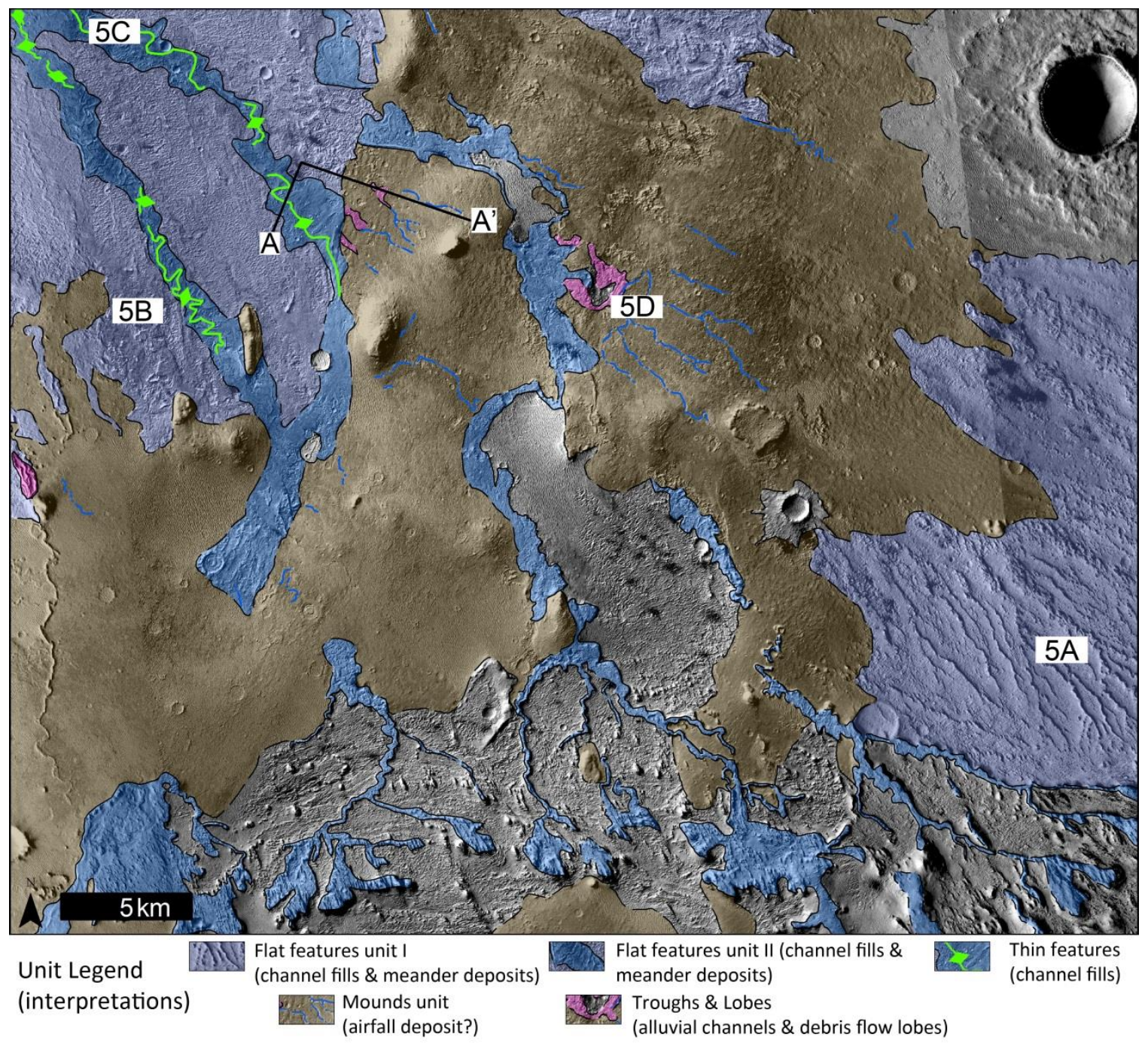

Figure SI-4. Area 40 mapped with 5 units, as they appear in the CTX mosaic. Thin blue delineations are sinuous troughs, some of which connect to lobes (shaded pink). We interpret the coincidence of these troughs and lobes as alluvial channels and debris-flow lobes, respectively. Grey areas are units of craters, impact ejecta, and aeolian material. Letters correspond to the ends of topographic profiles derived from CTX stereo DTMs. 

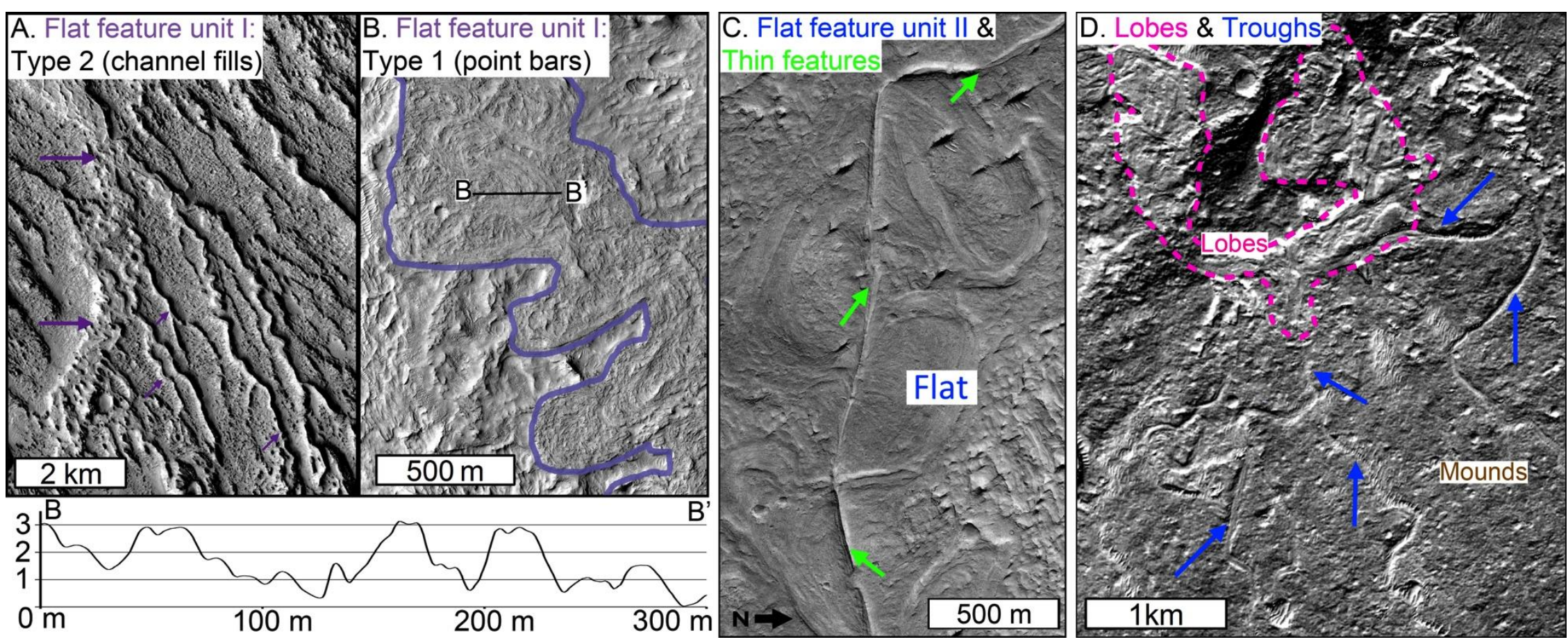

Figure SI-5. (A) Type 2 flat features form sub-parallel networks of ridges. Based on their relatively textureless upper surfaces, these networks are interpreted as many interconnected fluvial channel fills. (B) Portion of HiRISE image (PSP_006683_1740) shows a Type 1 flat feature. HiRISE DTM profile B-B' shows that the upper surface of this feature has meter-scale ridges and swales, interpreted to be eroded meander deposits. (C) A thin feature (green arrows) appears above a Type 1 flat feature of unit II and is consistent with the morphology of a fluvial channel fill. (D) Sinuous troughs (blue arrows) appear in the mounds unit and are connected to lobes (pink dashed outline). The troughs and lobes are interpreted as alluvial channels and debris-flow deposits, respectively. 


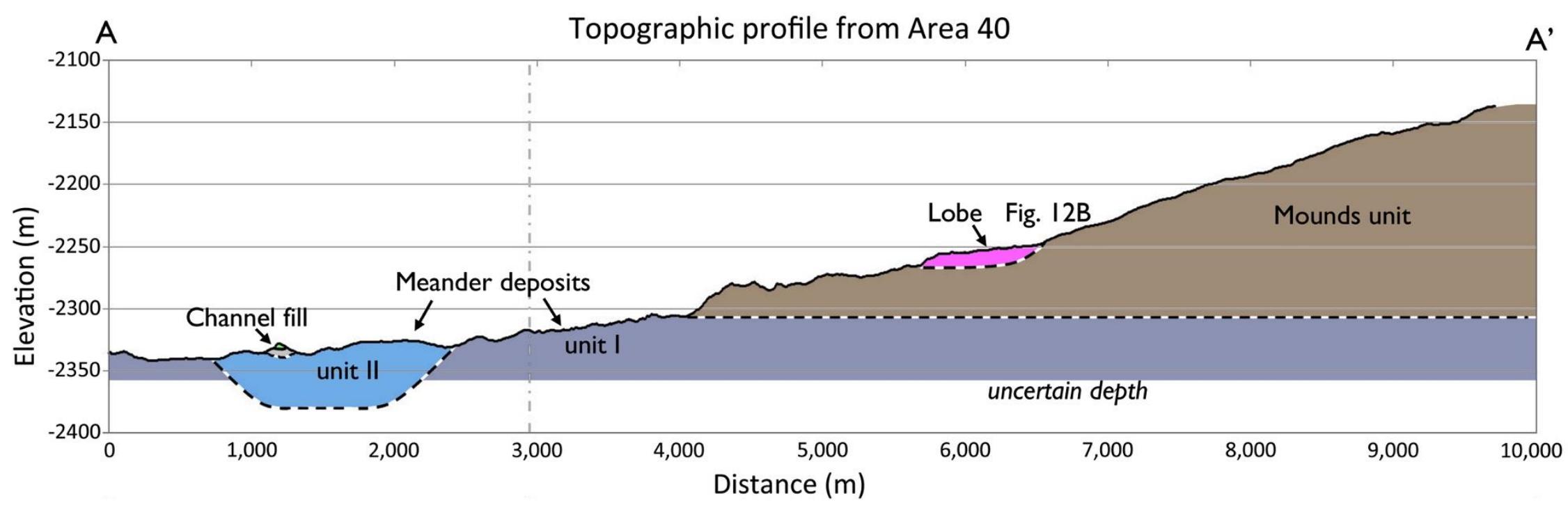

Figure SI-6. Profile A-A' from a CTX stereo DEM shows the topography and inferred stratal geometries of units in this area. Vertical gray line marks the near right-angle turn in profile heading. 


\section{Mapping of Area 45N}

Area $45 \mathrm{~N}$ is the northern of the two areas in northwest Aeolis Dorsa. A cratered unit is exposed in the northwest corner of the mapping area (Figure SI-7). This unit has smooth surfaces between craters, and a wrinkle ridge (Figure SI-8A), both of which are consistent with features on lava plains north of Aeolis Dorsa (Kerber and Head, 2010 and references therein). An impact crater with sea-urchin-like morphology similar to craters formed in the MFF (Kerber and Head, 2010) is superposed on this lava plain (Figure SI$8 \mathrm{~A}$ ) indicating that the MFF previously extended over this area.

Type 2 flat features in this area have widths of a couple hundred meters and textureless surfaces consistent with fluvial channel fills (Figure SI-8B). Channel fills converge eastward into a large fluvial deposit that is covered by NW-SE yardangs (Figure SI-8C). Thin features superpose both the individual fluvial channel fills and the large fluvial deposit. These thin features have flat upper surfaces, consistent with fluvial channel fills, and indicate a second episode of hydrologic activity and sedimentation. The broad deposit of channel fills connects with Aeolis Serpens in the northeast portion of Area $45 \mathrm{~N}$. Fluvial deposits in Area $45 \mathrm{~N}$ are sinuous along some of their lengths, but do not show evidence for lateral migration, i.e., meandering.

A plateau unit appears in the eastern portion of Area 45N (Figure SI-7). One fan feature connects to the plateau (Figure SI-8E). Several fans form on the west side of Area $45 \mathrm{~N}$ and are surrounded by yardangs. Fan features in Area $45 \mathrm{~N}$ form ridges and wide deposits with flat upper surfaces, which are consistent with sheetflood and/or channelized deposits. The fans suggest a change in topography and hydrology (e.g., intermittency of flow) relative to the fluvial deposits. However, in contrast to the fans in southern Aeolis Dorsa, fan deposits in Area 45N exhibit no evidence for debris flows.

\section{Stratigraphy of Area 45N}

We examine the stratigraphy of the 7 mapped units in Area $45 \mathrm{~N}$ in conjunction with a segmented topographic profile (Figure SI-9) to derive the stratigraphic column (Figure 10). The cratered lava unit exposed in the northwest corner of the mapping area is the topographically lowest unit, as shown in the topographic profile A-A' (Figure SI9). The topography of the cratered lava suggests that it is flat lying and may project beneath other units in the area.

The plateau unit appears in the eastern portion of Area $45 \mathrm{~N}$ and is older than fluvial deposits and alluvial fans based on superposition and embayment relationships. Flat and thin fluvial channel fills appear to converge towards the plateau unit in southern Area 45 N. From southern Area 45N, these fluvial channel fills form a wide deposit that extends to the north and then to the east, possibly wrapping around the plateau unit. Based on this geospatial arrangement, we infer that the wide deposit of fluvial channel fills embays (i.e., on-laps) the plateau unit. This inference implies that the plateau unit is older than fluvial units in Area 45N. Therefore, we place the plateau unit below fluvial units.

Fluvial channel fills of flat features have reliefs of 200 and 150 meters on either end of topographic profile A-A' (Figure SI-9). This relief represents thick deposits, some of which are the fluvial channel fills observed at the surface. The remaining deposits are interpreted to be one or multiple units of MFF that forms yardangs throughout the area. The fluvial channel fills in southwestern Area $45 \mathrm{~N}$ have widths of up to $\sim 750$ meters, 
which suggests a maximum deposit thickness of 25 meters. We interpret this wide deposit to be an amalgamation of the much smaller fluvial channel fills rather than a single channel. Therefore, assuming the same 750-m width for all the amalgamated fluvial channel fills, we place a 25 -meter-thick unit of fluvial channel fill above a 125meter-thick unit of MFF in the stratigraphic column (Figure 10).

Aeolis Serpens appears in the northeast corner of Area $45 \mathrm{~N}$ and is covered twice by the topographic profile A-A'. The profile shows that Aeolis Serpens has $\sim 25$ meters of relief. Aeolis Serpens has an average width of 500 meters, suggesting a thickness of $\sim 16$ meters.

Thin fluvial channel fills in southern Area $45 \mathrm{~N}$ have average widths of 60 meters, which suggest a thickness of 2 meters. The resolution of MOLA topography is not sufficient to resolve the relief of these fluvial channel fills. We assume a relief of 10 meters, based on the reliefs of similar channel fills in Area 40. We give the thin channel fills a jagged lower contact with Aeolis Serpens to indicate that this relationship is not known. Rather than thin channel fills forming before Aeolis Serpens, we prefer the interpretation that the paleochannel Aeolis Serpens came after the flat features unit. This preferred interpretation is based on the regional extent of Aeolis Serpens suggesting an episode of widespread and perhaps through-flowing hydrologic activity (Williams et al., 2013). Such hydrologic activity is similar to that implied by widespread fluvial deposits of flat features.

One alluvial fan and corresponding drainage network appear in eastern Area $45 \mathrm{~N}$ (Figure SI-7). The topographic profile A-A' suggests that the alluvial fan is $\sim 100$ meters higher than the fluvial channel fills. However, the profile suggests a fan thickness of only 40 meters, implying that the remaining 60 meters is some other material beneath the fan. We suggest that this material is another unit of MFF deposited over the fluvial channel fills and then covered by the alluvial fan. This second deposit of MFF would explain the origins of the yardangs that cover fluvial channel fills. Based on this inference, we place a 60-meter-thick unit of MFF beneath a 40-meter-thick unit of fan material in the stratigraphic column for Area 45N (Figure 10). In the stratigraphic column, we do not give the alluvial clasts a color because fans in Area $45 \mathrm{~N}$ are comprised of either sheetfloods or channelized deposits, and not debris flow deposits. 


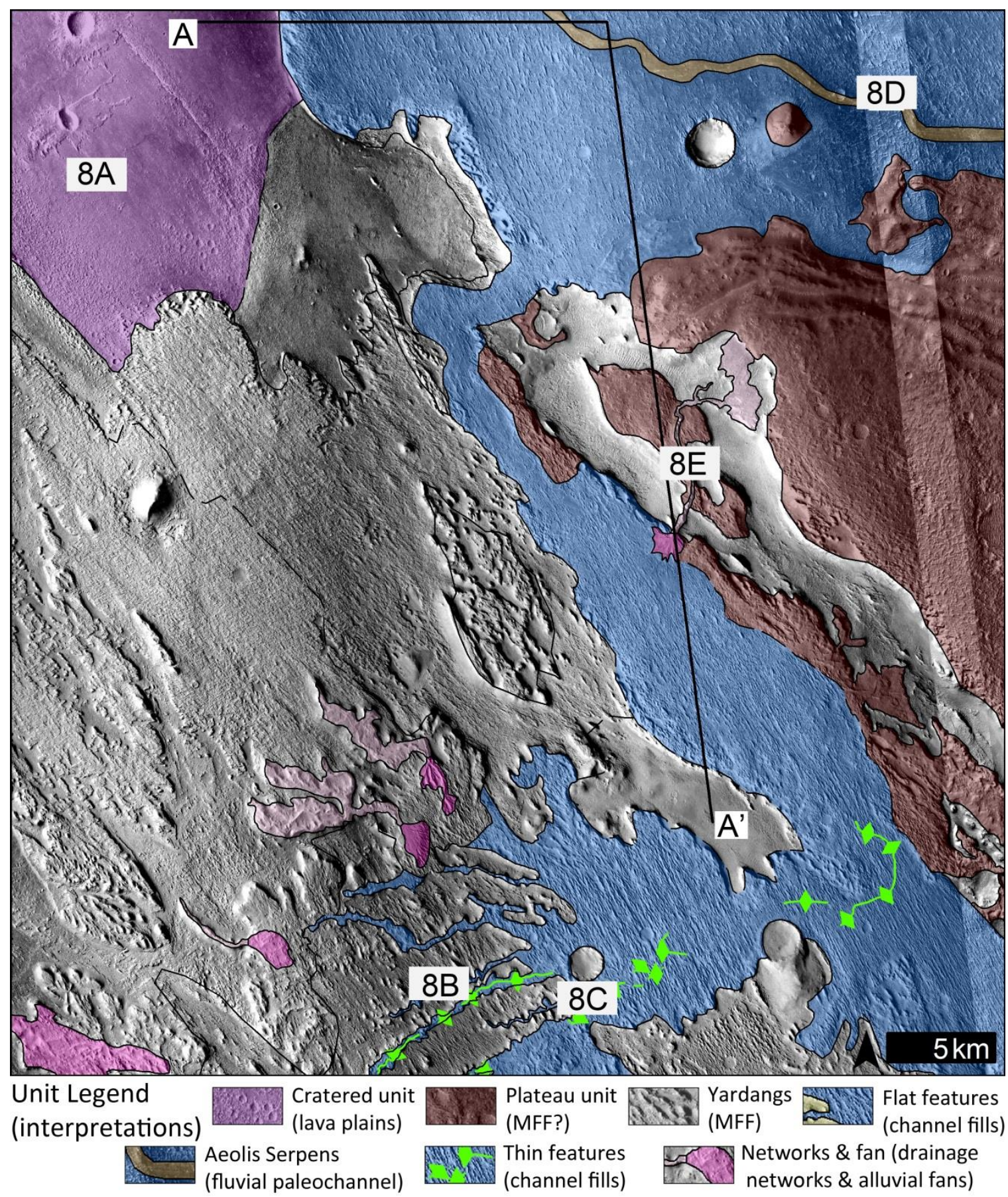

Figure SI-7. Area 45N mapped with 7 units, as they appear in the CTX mosaic. Letters identifiers correspond to the ends of topographic profiles derived from CTX stereo DTMs. 


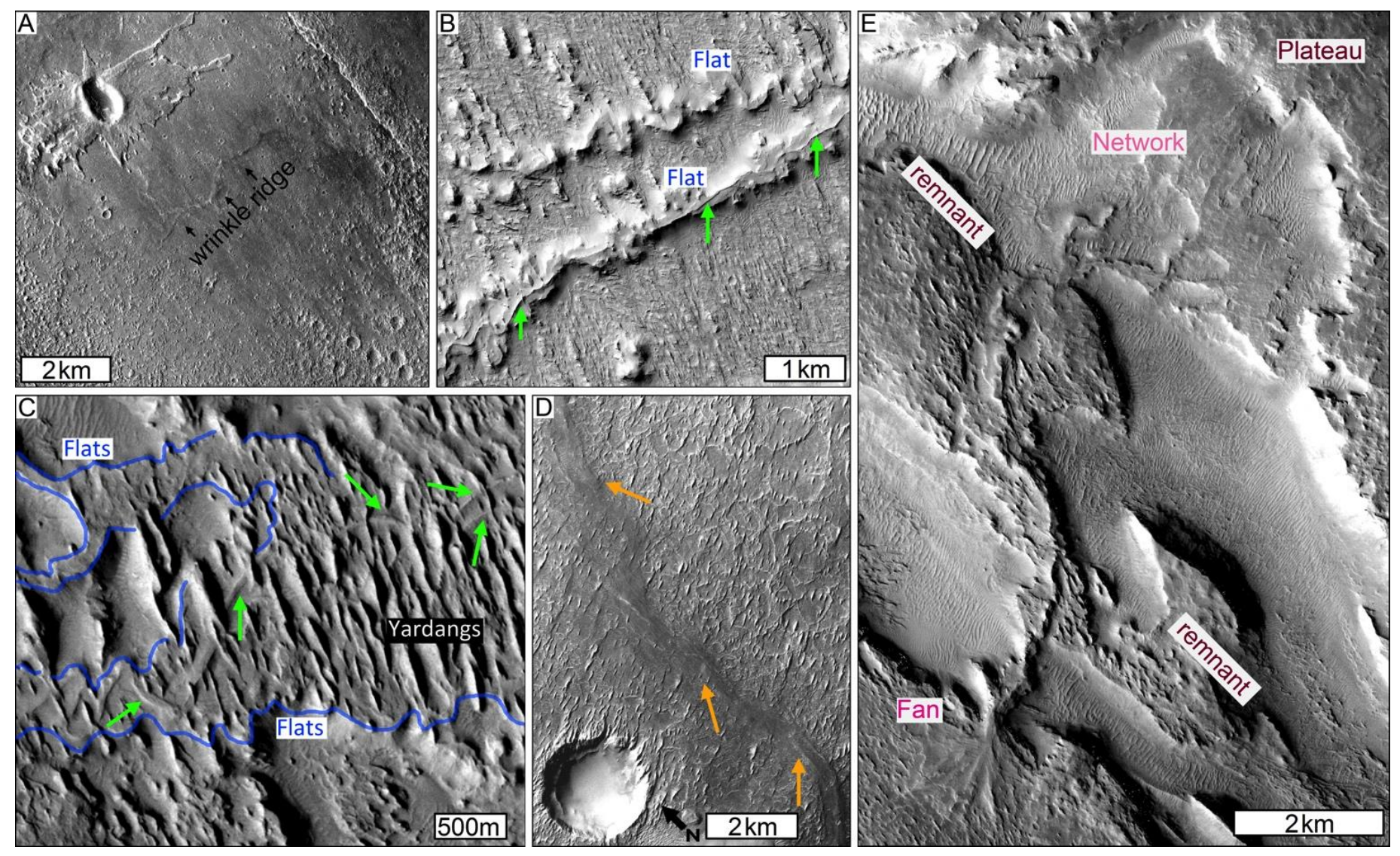

Figure SI-8. (A) The cratered unit has smooth surfaces between many small craters and a wrinkle ridge, similar to lavas north of Aeolis Dorsa (Kerber and Head, 2010 and references therein). (B) Type 2 flat features have textureless upper surfaces that we interpret as fluvial channel fills. The fluvial channel fill at the bottom of the image has a thin channel fill (green arrow) on its upper surface. These ridges connect eastward and form a large deposit with three units. (C) Three units of the large deposit are fluvial channel fills of flat features (blue outlines), thin superposing channel fills (green arrows), and NW-SE yardangs. (D) In this map area, Aeolis Serpens exhibits twin lateral ridges (orange arrows). (E) Fan and network units appear adjacent to the plateau unit. The fan is small and consists of wide and flat ridges that are morphologically consistent with sheetflood and/or channelized deposits. 


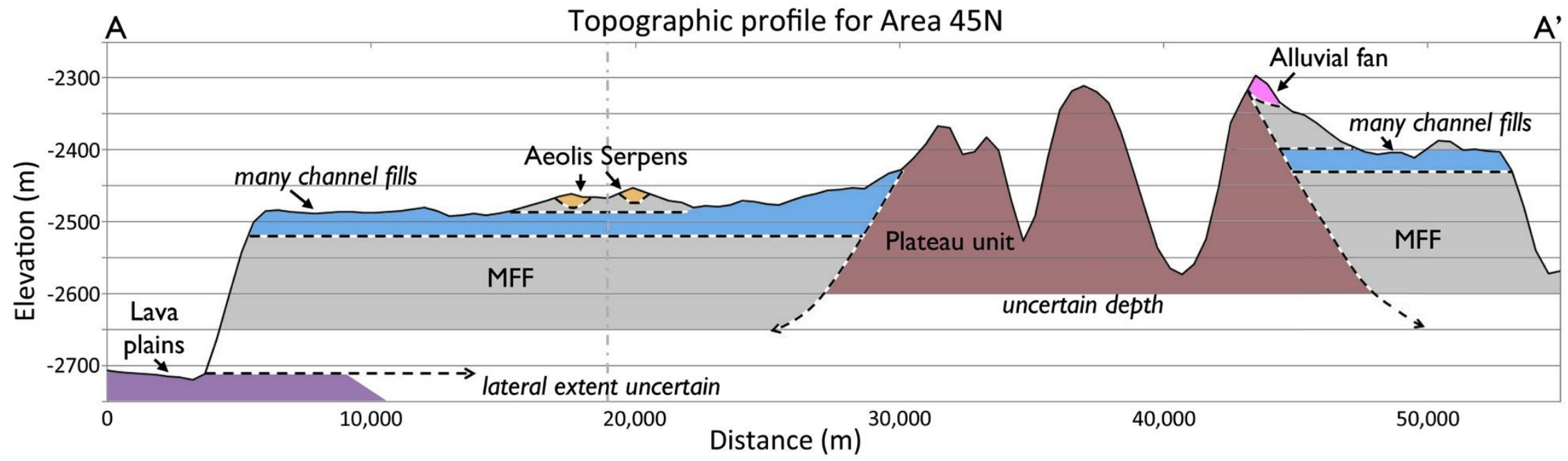

Figure SI-9. Topographic profile through Area 45N. Profile A-A' from MOLA gridded DEM shows the surface topography and inferred subsurface relationships of units. Vertical gray line marks the right turn in profile heading towards the south. 


\section{Mapping of Area 45S}

Area $45 \mathrm{~S}$ is located along the eastern margin of Aeolis Planum. The northeast corner of the mapping area (Figure SI-10) exhibits a cratered unit with a smooth surface, a wrinkle ridge, and craters (Figure SI-11A). As in Area 45N, we interpret this unit as lava. A large portion of Area $45 \mathrm{~S}$ is covered by yardangs with NW-SE orientations. These aeolian features indicate deposition of MFF followed by induration, and then abrasion from a sediment-bearing NW-SE paleo-wind.

Flat features in the map area have nondescript upper surfaces (Figure SI-11B), which are similar to the upper surfaces of terrestrial channel fills. No evidence of meander deposits was observed. Thin features have sharp crests rather than flat upper surfaces (Figure SI-11C). We attribute the sharp-crest morphology to aeolian abrasion and interpret the thin ridges as eroded channel fills. Thin channel fills also appear on top of flat features.

Fans in Area 45S have broad flat ridges or thin sinuous ridges (Figure 12F). These morphologies are consistent with sheetflood or channelized deposits. No pairs of parallel ridges, indicative of debris flow deposits, were observed in Area 45S.

\section{Stratigraphy of Area 45S}

We examine the stratigraphy of the 6 mapped units in Area $45 \mathrm{~S}$ in conjunction with a topographic profile (Figure SI-12) to derive the stratigraphic column (Figure 10). Like Area 45N, Area 45S also has a cratered lava unit. The topographic profile shows that these lava plains are the topographically lowest unit. Therefore, we place this unit at the bottom of the stratigraphic column, suggesting that all other units (e.g., MFF) have been emplaced on to these lava plains.

Aeolis Planum in Area 45S does not contact any fluvial or alluvial fan units. However, remnants of drainage networks are connected to fan apices and are oriented towards Aeolis Planum (i.e., in a northeast-southwest direction), suggesting that larger, now eroded, drainage networks may have extended towards Aeolis Planum. Like Zephyria Planum in Area 35, we interpret the current position of Aeolis Planum to be the product of cliff-retreat towards the southwest. Based on this interpretation, we place Aeolis Planum beneath alluvial and fluvial units in the stratigraphic column (Figure 10).

Fluvial channel fills of flat features form networks in Area 45S. The topographic profile shows that channel fills have reliefs on the order of 200 meters and an average width of $\sim 450$ meters (Figure SI-12). These dimensions suggest an average thickness of 15 meters for the fluvial deposit and 185 meters of MFF to account for the remaining relief. Thin fluvial channel fills are discontinuous in Area 45S (Figure 16), but have reliefs on the order of 10 meters and an average width of $\sim 45$ meters, suggesting an average thickness of 3 meters.

Alluvial fans appear in the southern and northwestern portions of Area 45S (Figure SI-10). The topographic profile shows the top of the alluvial fan is 200 meters above the fluvial units (Figure SI-12). The relief of only the fan area suggests a fan thickness of 80 meters, implying that the remaining 120 meters is some other material (e.g., MFF) beneath the fan. 


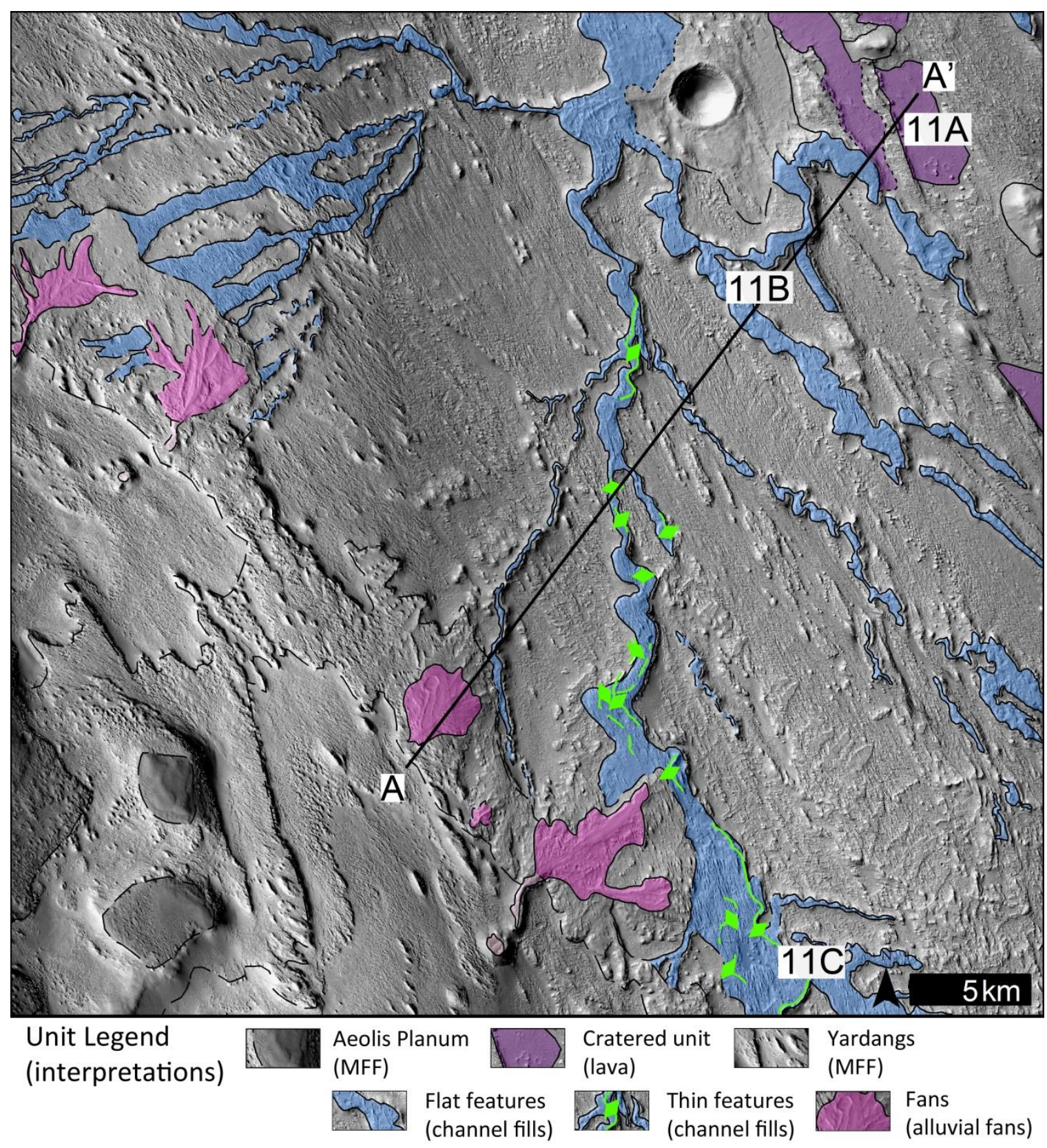

Figure SI-10. Mapping of Area 45S suggests 6 units as they appear in the CTX mosaic. Dark grey unit in the southwest corner corresponds to the eastern margin of Aeolis Planum. Letters correspond to ends of topographic profiles derived from CTX stereo DTMs. 

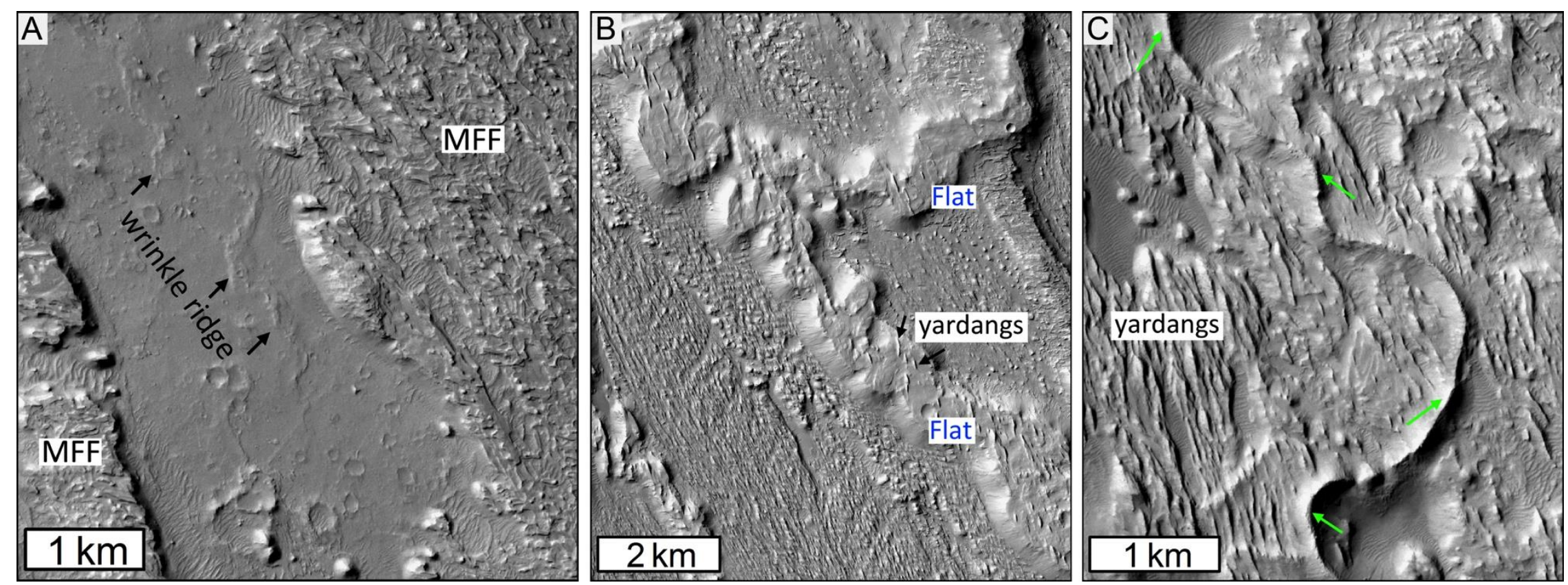

Figure SI-11. Examples of units in Area 45S. (A) A cratered unit has a smooth surface texture between many small craters and a wrinkle ridge. As for Area 45N, we interpret the cratered unit as lava. (B) Type 2 flat features are consistent with fluvial channel fills based on their flat, textureless upper surfaces. Yardangs with NW-SE orientations appear on the upper surfaces of fluvial channel fills, similar to Area 45N. (C) Thin feature with a sharp crests (green arrows) suggests an eroded fluvial channel fill. 


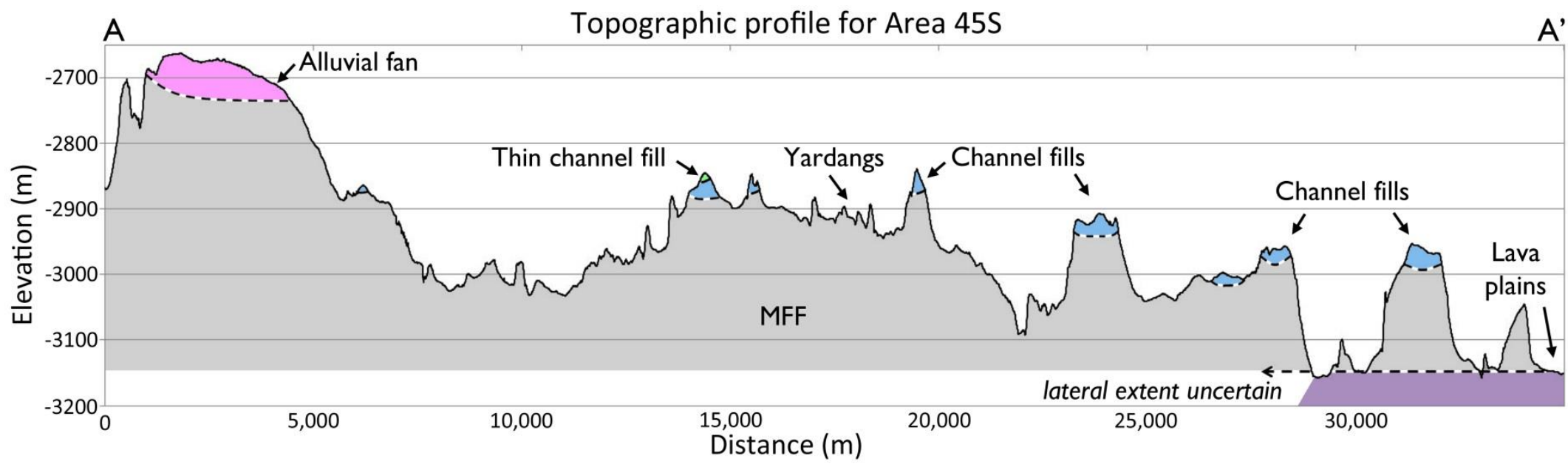

Figure SI-12. Topographic profile through Area 45S. Profile A-A' from a CTX DTM shows the topography of units in Area 45S. 